\title{
Effects of Renin-Angiotensin System Inhibitors on the Occurrence of Acute Kidney Injury Following Off-Pump Coronary Artery Bypass Grafting
}

\author{
Young Chul Yoo, MD; Young-Nam Youn, MD, PhD; Jae Kwang Shim, MD, PhD; \\ Jong Chan Kim, MD; Na Young Kim, MD; Young Lan Kwak, MD, PhD
}

\begin{abstract}
Background: Despite several studies that evaluated the effects of renin-angiotensin system (RAS) inhibitors on postoperative renal function in cardiac surgery patients, no final conclusions are available. The aim of the present study was to determine the effect of RAS inhibitors on renal function following off-pump coronary artery bypass grafting (OPCAB).
\end{abstract}

Methods and Results: Among patients who underwent OPCAB, perioperative characteristics, postoperative renal function and incidence of acute kidney injury (AKI) were compared between those who received RAS inhibitors for at least 2 weeks (RASI group, $n=296$ ) and those not treated with RAS inhibitors (Control group, $n=176$ ). AKI was defined as an increase in serum creatinine $>0.3 \mathrm{mg} / \mathrm{dl}$ or $>50 \%$ from baseline. Preoperative comorbidities were more frequent in the RASI group. Operative data were similar. Incidence of postoperative AKI (19.9\% vs $20.9 \%, P=0.815$ ) and of postoperative renal function was comparable between groups. In the adjusted multivariate logistic regression model for propensity scores between groups, diabetes mellitus, preoperative creatinine level and perioperative transfusion were significant risk factors for postoperative AKI, whereas preoperative treatment with RAS inhibitors did not increase the risk.

Conclusions: Chronic preoperative use of RAS inhibitors did not affect postoperative renal function or increase the risk of postoperative AKI in patients undergoing OPCAB. (Circ J 2010; 74: 1852-1858)

Key Words: Acute kidney injury; Off-pump coronary artery bypass grafting; Renin-angiotensin system inhibitors

A $\mathrm{s}$ the indications for renin-angiotensin system (RAS) inhibitors expand for secondary prevention in patients with coronary artery disease,$^{1}$ an increasing number of patients presenting for coronary artery bypass graft surgery $(\mathrm{CABG})$ have had chronic angiotensin-converting enzyme inhibitor or angiotensin receptor blocker administration. Although continued RAS inhibitor therapy is associated with improved survival and retarded progression of renal disease, ${ }^{2-4}$ concerns about the development acute kidney injury (AKI) in situations associated with decreased glomerular filtration pressure have been raised..$^{2,5,6}$

\section{Editorial $\mathrm{p} 1800$}

Indeed, cardiac surgery under cardiopulmonary bypass $(\mathrm{CPB})$ is significantly associated with changes in the glomerular filtration rate and volume shift. Chronic preoperative
RAS inhibitor therapy reportedly resulted in $28 \%$ increased risk of AKI following cardiac surgery, suggesting withholding of these medications prior to surgery. ${ }^{2}$ However, from the currently available evidence no definite conclusion can be drawn on withdrawing RAS inhibitors prior to CABG at the expense of losing their anti-ischemic benefits., ${ }^{2,7}$

Use of the off-pump CABG (OPCAB) technique in patients presenting with high surgical risk has increased, with preferable results. ${ }^{8-10} \mathrm{CPB}$ itself is considered one of the main etiologic factors in the development of AKI. ${ }^{11-14}$ In addition, because RAS inhibitor-associated AKI is more likely to develop under certain conditions, such as hypovolemia and renal hypoperfusion, ${ }^{15,16}$ we hypothesized that preload augmentation before distal anastomosis and maintenance of pulsatile blood flow and pressure during surgery would mitigate the effect of RAS inhibitors on renal function after OPCAB. However, comprehensive data to support

Received March 17, 2010; revised manuscript received April 21, 2010; accepted May 6, 2010; released online July 10, 2010 Time for primary review: 25 days

Department of Anesthesiology and Pain Medicine (Y.C.Y., J.C.K., N.Y.K., J.K.S., Y.L.K.), Division of Cardiovascular Surgery (Y.-N.Y.), Anesthesia and Pain Research Institute (J.K.S., Y.L.K.), Yonsei University Health System, Seoul, South Korea

Name of grant: no fund supported.

Mailing address: Young Lan Kwak, MD, PhD, Department of Anesthesiology and Pain Medicine and Anesthesia and Pain Research Institute, Yonsei University Health System, 250 Seongsanno, Seodaemun-gu, Seoul 120-752, South Korea. E-mail: ylkwak@yuhs.ac

ISSN-1346-9843 doi:10.1253/circj.CJ-10-0261

All rights are reserved to the Japanese Circulation Society. For permissions, please e-mail: cj@j-circ.or.jp 
this do not exist and thus the purpose of the present study was to evaluate the influence of continued preoperative chronic RAS inhibitor therapy on the occurrence of AKI and postoperative renal function following $\mathrm{OPCAB}$.

\section{Methods}

Between March 2006 and November 2009, data for 513 consecutive patients who underwent OPCAB were collected. We analyzed patients undergoing isolated OPCAB and matched the following characteristics: procedure performed without CPB; neither chronic renal failure and/or renal failure requiring dialysis, normal preoperative serum creatinine (Cr) level $(\mathrm{Cr}<1.5 \mathrm{mg} / \mathrm{dl})$, and preoperative treatment with RAS inhibitors for no more than 2 weeks before surgery. All patients treated with RAS inhibitors for at least 2 weeks and which continued to the day of operation constituted the RAS inhibitor (RASI) group. They were compared with the remaining patients who had not had chronic preoperative RAS inhibitor therapy (Control group). The primary endpoint was the occurrence of AKI after OPCAB. AKI was defined using the modified RIFLE classification: stage 1 was elevation of serum $\mathrm{Cr} \geq 0.3 \mathrm{mg} / \mathrm{dl}$ or $50-200 \%$ from baseline; stage 2, 200-300\%; stage 3, $>4 \mathrm{mg} / \mathrm{dl}$ or $>300 \% .^{17,18}$

We prospectively reviewed the electronic medical records of these patients under the approval of the institutional review board.

\section{Data Collection}

Although data were collected retrospectively from the using electronic medical records, all variables were prospectively evaluated and patients were managed under tight control of hemodynamic and fluid management according to the institutional protocol. Preoperative variables included demographics, medications, comorbid conditions, including New York Heart Association Functional Classification (NYHA), left ventricular ejection fraction (EF), presence of chronic obstructive lung disease, cerebrovascular accidents, hypertension, and/or diabetes mellitus (DM), and emergency operation. We also measured the risk of acute renal failure (ARF) after cardiac surgery by using the Cleveland Clinic Foundation scoring system $^{19}$ and the risk of early mortality in cardiac surgical patients by using EuroSCORE. ${ }^{20}$ Intraoperative variables included number of grafts, use of vasopressors, fluid and cell saver input, urine output, hemodynamic data, including cardiac index, mixed venous oxygen saturation $\left(\mathrm{SvO}_{2}\right)$, arterial pressure, central venous pressure (CVP), heart rate, pulmonary capillary wedge pressure (PCWP) and pulmonary arterial pressure (PAP). Intraoperative hemodynamic variables were recorded at predetermined time points (ie, $20 \mathrm{~min}$ after induction, $7 \mathrm{~min}$ after application of stabilizer for each distal anastomosis and after sternal closure). Postoperative variables included occurrence of AKI, dialysis, atrial fibrillation (AF), duration of intensive care unit (ICU) stay and hospital stay, occurrence of re-intubation and death, use of milrinone, and perioperative transfusion. Serum $\mathrm{Cr}$, creatine kinase (CK)$\mathrm{MB}$, and troponin- $\mathrm{T}$ were measured serially preoperatively and on postoperative day (POD) $0,1,2$, and 7 . Changes in serum $\mathrm{Cr}$ levels from the baseline values $(\Delta \mathrm{Cr})$ and $\mathrm{Cr}$ clearance $(\mathrm{CrCl})$ were calculated at the same time points. The volume of packed red blood cell transfusion during the intraoperative period and 5 postoperative days were recorded. Operative mortality was defined as all deaths that occurred during the hospital stay or after hospital discharge but within 30 days postoperatively.

\section{Anesthetic Management and Surgical Technique}

Cardiac medications were continued until the morning of surgery, except for diuretics and antiplatelet agents. All patients received $0.05-0.1 \mathrm{mg} / \mathrm{kg}$ of morphine intramuscularly as premedication $1 \mathrm{~h}$ before operation. Upon arrival at the operating room, standard monitoring devices were applied, including a pulmonary artery catheter (Swan-Ganz CCOmbo $\mathrm{CCO} / \mathrm{SvO}_{2}{ }^{\mathrm{TM}}$, Edwards Lifesciences LLC, Irvine, CA, USA), which was inserted via the right internal jugular vein and connected to an analysis system (Vigilance ${ }^{\mathrm{TM}}$, Edwards Lifesciences) for continuous monitoring of the cardiac index and $\mathrm{SvO}_{2}$. The radial artery was also cannulated in all patients with a $20-\mathrm{G}$ cannula for continuous arterial pressure monitoring. Anesthesia was induced with intravenous midazolam $(0.03-0.07 \mathrm{mg} / \mathrm{kg})$ and sufentanil $(1.5-2.0 \mu \mathrm{g} / \mathrm{kg})$, and maintained with sevoflurane $(0.8-1.5 \%)$ and continuous infusion of sufentanil $\left(0.5-1.5 \mu \mathrm{g} \cdot \mathrm{kg}^{-1} \cdot \mathrm{h}^{-1}\right)$. Neuromuscular blockade was achieved by administering rocuronium $(0.9 \mathrm{mg} / \mathrm{kg})$ and maintained with continuous infusion of vecuronium $(1-2 \mu \mathrm{g}$. $\left.\mathrm{kg}^{-1} \cdot \mathrm{min}^{-1}\right)$. Isosorbide dinitrate $\left(0.5 \mu \mathrm{g} \cdot \mathrm{kg}^{-1} \cdot \mathrm{min}^{-1}\right)$ was infused in all patients. The patients' lungs were ventilated with a tidal volume of $8-10 \mathrm{ml} / \mathrm{kg}, \mathrm{I}: \mathrm{E}$ ratio of $1: 2$, at a rate of $8-12$ breaths/min in $40 \%$ oxygen with air and a positive end-expiratory pressure of $5 \mathrm{cmH}_{2} \mathrm{O}$ during surgery. After induction of anesthesia, a transesophageal echocardiography probe was inserted to assess global cardiac function and detect newly developing segmental wall motion abnormalities and mitral regurgitation. All surgical procedures were performed by 2 surgeons through a median sternotomy and the heart was displaced using a posterior pericardial stitch, large $(12 \times 70 \mathrm{~cm})$ gauze swabs and a tissue stabilizer (Octopus Tissue Stabilization System ${ }^{\circledR}$, Medtronic Inc, USA). Intravascular volume replacement was managed with crystalloid and colloid solutions to maintain the PCWP between 8 and $16 \mathrm{mmHg}$ according to the baseline values prior to manipulation of the heart and after completion of grafting. During the period of heart displacement, crystalloid solution was infused at a fixed rate of $6-8 \mathrm{ml} \cdot \mathrm{kg}^{-1} \cdot \mathrm{h}^{-1}$, whereas colloid solution was infused to compensate for the amount of blood loss collected by a cell salvage device. Salvaged blood by the cell salvage device was re-infused to the patient before the end of the surgery. Hemodynamic management was as follows: (1) maintenance of mean arterial pressure (MAP) between 60 and $80 \mathrm{mmHg}$ either with norepinephrine or nicardipine infusion (between 65 and $75 \mathrm{mmHg}$ with either $10-20^{\circ}$ Trendelenburg's position and/or norepinephrine infusion during heart displacement), (2) infusion of milrinone in patients with $\mathrm{SvO}_{2}<60 \%$ for $\geq 10 \mathrm{~min}$ and/or development of mitral regurgitation $\geq$ grade 3 with concomitant rise in mean PAP $>30 \mathrm{mmHg}$. Throughout the study period, packed red blood cells were transfused when the hematocrit level was $<25 \%$. Central temperature measured by pulmonary artery catheter was maintained between $36^{\circ} \mathrm{C}$ and $37^{\circ} \mathrm{C}$ with warm mattress, forced warm air blanket and fluid warmer as necessary. All patients were transferred to the ICU after the surgery.

\section{Statistical Analysis}

Continuous variables are shown as mean \pm SD or median with interquartile range, categorical variables are shown as number (percentage). Comparisons were made with Student's t-test/Mann-Whitney $U$ test or $\chi^{2} /$ Fisher exact test as appropriate. To identify independent predictor of AKI, a logistic regression model was used. Potential confounding factors for analysis were selected on the basis of a literature review and 


\begin{tabular}{lccr|}
\hline Table 1. Patient Demographics and Preoperative Clinical Data & & \\
Age (years) & Control $(\mathbf{n}=\mathbf{1 7 6})$ & RASI $(\mathbf{n}=\mathbf{2 9 6})$ & P value \\
Female & $65 \pm 7$ & $65 \pm 9$ & 0.689 \\
BMI $\left(\mathrm{kg} / \mathrm{m}^{2}\right)$ & $76(43.2)$ & $107(36.1)$ & 0.129 \\
NYHA & $24 \pm 3$ & $25 \pm 3$ & 0.157 \\
I-II & & & \\
III-IV & $166(94.3)$ & $267(90.2)$ & \\
DM & $10(5.7)$ & $29(9.8)$ & 0.116 \\
Hypertension & $56(31.8)$ & $129(43.6)$ & 0.011 \\
Ejection fraction $(\%)$ & $108(61.4)$ & $203(68.6)$ & 0.011 \\
Preoperative CrCl $<60(\mathrm{ml} / \mathrm{min})$ & $61 \pm 10$ & $56 \pm 14$ & $<0.001$ \\
Medications & $80(45.5)$ & $125(42.2)$ & 0.494 \\
Aspirin & & & \\
Plavix & $144(81.8)$ & $251(84.8)$ & 0.397 \\
$\beta$-blockers & $130(73.9)$ & $222(75.3)$ & 0.737 \\
CCB & $114(64.8)$ & $205(69.3)$ & 0.314 \\
Antilipid & $103(58.5)$ & $120(40.5)$ & $<0.001$ \\
Diuretics & $81(46)$ & $151(51)$ & 0.294 \\
ARF score & $16(9.1)$ & $54(18.2)$ & 0.007 \\
EuroSCORE & $1.0 \pm 1.0$ & $1.2 \pm 1.2$ & 0.111 \\
Valus & $3.2 \pm 2.1$ & $4.1 \pm 2.3$ & $<0.001$ \\
\hline
\end{tabular}

Values are mean \pm SD or no. of patients (\%).

RASI, renin-angiotensin system inhibitors; BMI, body mass index; NYHA, New York Heart Association Functional Classification; $\mathrm{DM}$, diabetes mellitus; $\mathrm{CrCl}$, creatinine clearance; $\mathrm{CCB}$, calcium-channel blockers; ARF, acute renal failure.

\begin{tabular}{|lccc|}
\hline Table 2. Intraoperative Parameters & & & \\
& Control $(\mathbf{n}=\mathbf{1 7 6})$ & RASI $(\mathbf{n}=\mathbf{2 9 6})$ & P value \\
Anesthesia time $(\mathrm{min})$ & $319 \pm 52$ & $316 \pm 53$ & 0.618 \\
Emergency operation & $1(0.6)$ & $5(1.7)$ & 0.419 \\
No. of grafts & $3.2 \pm 0.8$ & $3.3 \pm 0.8$ & 0.107 \\
Amount of norepinephrine infused $(\mu \mathrm{g})$ & $212 \pm 179$ & $292 \pm 311$ & 0.004 \\
Fluid balance & & & \\
Crystalloid $(\mathrm{ml})$ & $2,792 \pm 964$ & $2,816 \pm 1,145$ & 0.814 \\
Colloid $(\mathrm{ml})$ & $1,123 \pm 401$ & $1,031 \pm 475$ & 0.208 \\
Cell saver $(\mathrm{ml})$ & $210 \pm 189$ & $213 \pm 166$ & 0.831 \\
Urine output $(\mathrm{ml})$ & $742 \pm 425$ & $753 \pm 477$ & 0.797 \\
\hline
\end{tabular}

Values are mean \pm SD or no. of patients (\%).

Abbreviation see in Table 1.

included demographic data [age, sex, body mass index (BMI)], known risk factors for AKI after cardiac surgery (anesthesia time, NYHA class, DM, hypertension, emergency surgery, $\mathrm{EF}<35 \%$, and preoperative serum $\mathrm{Cr}$ ). Preoperative cardiac medications ( $\beta$-blockers, calcium-channel blockers, RAS inhibitors, and diuretics) were added in the analysis. First, univariate logistic regression analysis was performed to identify significant predictors of AKI using the variables and those that had a P-value $<0.05$ were included in the multivariate logistic regression analysis, as well as the demographic data, known risk factors, and RAS inhibitors. Odds ratios (OR) and associated $95 \%$ confidence intervals (CI) were estimated. We also estimated a propensity score using several covariates. We then used the propensity score to match patients (based on the nearest algorithm) who were taking RAS inhibitors with those who were not. After matching, we estimated the logistic model for AKI with several covariates. Patients with missing data for any of the covariates entered in the model were excluded. No attempt was performed to input data. Model fit was assessed with the Hosmer-Lemeshow good- ness-of-fit test. All analyses were done with SPSS 15.0 (SPSS Inc, Chicago, IL, USA). In all tests, $\mathrm{P}<0.05$ was considered significant.

\section{Results}

A total of 472 patients were included in this study [mean age, 64.9 \pm 8.4 years, median, 66 (61-70) years; mean BMI, $24.6 \pm 2.9 \mathrm{~kg} / \mathrm{m}^{2} ; 61 \%$ males; $39 \%$ had DM, $66 \%$ had hypertension, $8 \%$ had congestive heart failure; $63 \%$ of patients were preoperatively medicated with RAS inhibitors]. AKI developed in 35 patients $(19.9 \%)$ of the Control group and $62(20.9 \%)$ of the RASI group without significant difference between the groups $(\mathrm{P}=0.815)$. A total of 7 patients $(1.5 \%)$ required dialysis, comprising $1(0.6 \%)$ in the Control group and $6(2 \%)$ in the RASI group $(\mathrm{P}=0.266)$.

Demographic data and ARF scores were comparable between the groups. In the RASI group, the numbers of patients with DM, hypertension and those being treated with diuretics were significantly greater than in the Control group, 
Table 3. Changes in Intraoperative Hemodynamic Parameters

\begin{tabular}{|c|c|c|c|c|c|c|}
\hline & \multicolumn{2}{|c|}{ Post induction } & \multicolumn{2}{|c|}{ OM } & \multicolumn{2}{|c|}{ Sternum closure } \\
\hline & Control & RASI & Control & RASI & Control & RASI \\
\hline $\mathrm{Cl}\left(\mathrm{L} \cdot \mathrm{min}^{-1} \cdot \mathrm{m}^{-2}\right)$ & $2.8 \pm 0.6$ & $2.8 \pm 0.6$ & $2.1 \pm 0.5$ & $2.1 \pm 0.4$ & $2.6 \pm 0.6$ & $2.6 \pm 0.5$ \\
\hline $\mathrm{SvO}_{2}(\%)$ & $78.4 \pm 5.5$ & $78.2 \pm 5.6$ & $66.9 \pm 8.5$ & $67.5 \pm 8$ & $71.8 \pm 8.8$ & $73.1 \pm 7.2$ \\
\hline MAP $(\mathrm{mmHg})$ & $74.9 \pm 11.7$ & $72.2 \pm 10.1^{*}$ & $75.4 \pm 8.2$ & $72.8 \pm 7.3^{\star}$ & $78.2 \pm 8.8$ & $75.5 \pm 9.7^{*}$ \\
\hline CVP (mmHg) & $7.8 \pm 2.7$ & $8.3 \pm 2.5^{*}$ & $9.7 \pm 2.6$ & $10.1 \pm 2.6^{\star}$ & $8.6 \pm 2.5$ & $9 \pm 2.6$ \\
\hline HR (beats/min) & $61.3 \pm 10.9$ & $61.7 \pm 10.2$ & $65.2 \pm 9.9$ & $65.7 \pm 10.2$ & $69.7 \pm 10.3$ & $70 \pm 10.9$ \\
\hline PCWP (mmHg) & $12 \pm 3.4$ & $12.7 \pm 4.1$ & $13.6 \pm 3.2$ & $14.2 \pm 3.4$ & $12.8 \pm 2.9$ & $13.6 \pm 3.2^{*}$ \\
\hline mPAP $(\mathrm{mmHg})$ & $16.5 \pm 3.8$ & $17.5 \pm 4.1^{*}$ & $18.9 \pm 4.2$ & $19.8 \pm 4.8^{*}$ & $17.1 \pm 3.4$ & $18.3 \pm 3.7^{*}$ \\
\hline
\end{tabular}

Values are mean $\pm S D$. * $P<0.05$ vs control group.

Post induction, $15 \mathrm{~min}$ after induction of anesthesia; OM, $7 \mathrm{~min}$ after stabilizer application for obtuse marginalis branch anastomosis; Sternum closure, $15 \mathrm{~min}$ after sternum closure; $\mathrm{Cl}$, cardiac index; $\mathrm{SvO}_{2}$, mixed venous oxygen saturation; MAP, mean arterial pressure; CVP, central venous pressure; HR, heart rate; PCWP, pulmonary catheter wedge pressure; mPAP, mean pulmonary arterial pressure. Other abbreviation see in Table 1.

\begin{tabular}{|c|c|c|c|c|c|}
\hline Group & Preoperative & PODO & POD1 & POD2 & POD7 \\
\hline \multicolumn{6}{|c|}{ Serum $\mathrm{Cr}(\mathrm{mg} / \mathrm{dl})$} \\
\hline Control & $1 \pm 0.2$ & $0.79 \pm 0.2$ & $1 \pm 0.2$ & $1 \pm 0.3$ & $1 \pm 0.3$ \\
\hline RASI & $1 \pm 0.2$ & $0.84 \pm 0.2^{*}$ & $1 \pm 0.3$ & $1.1 \pm 0.4^{*}$ & $1.1 \pm 0.4^{*}$ \\
\hline \multicolumn{6}{|l|}{$\Delta \mathrm{Cr}(\mathrm{mg} / \mathrm{dl})$} \\
\hline Control & & $-0.2 \pm 0.1$ & $0 \pm 0.3$ & $0.1 \pm 0.2$ & $0 \pm 0.3$ \\
\hline RASI & & $-0.2 \pm 0.1$ & $0 \pm 0.2$ & $0.1 \pm 0.3$ & $0.1 \pm 0.3^{*}$ \\
\hline \multicolumn{6}{|l|}{$\mathrm{CrCl}(\mathrm{ml} / \mathrm{min})$} \\
\hline Control & $65.4 \pm 17.5$ & $81.3 \pm 21.7$ & $68.3 \pm 20$ & $64.5 \pm 21.3$ & $66.7 \pm 19.6$ \\
\hline RASI & $66.9 \pm 21.4$ & $81.7 \pm 25.7$ & $79.7 \pm 24.7$ & $64.8 \pm 25.2$ & $65.8 \pm 22.9$ \\
\hline \multicolumn{6}{|c|}{ CK-MB (ng/ml) } \\
\hline Control & $2.4(2.1-3.1)$ & $5(3.9-6.4)$ & $6.5(5.1-9.2)$ & $5.7(4.3-9)$ & $3.7(3-5.8)$ \\
\hline RASI & $2.6(2.2-3.3)$ & $5.3(4.2-6.9)$ & $6.8(5-9.5)$ & $5.3(4.2-8.2)$ & $3.6(2.8-4.6)$ \\
\hline \multicolumn{6}{|c|}{ Troponin-T (ng/ml) } \\
\hline Control & $0.001(0.001-0.001)$ & $0.09(0.05-0.12)$ & $0.09(0.06-0.14)$ & $0.07(0.05-0.12)$ & $0.05(0.03-0.09)$ \\
\hline RASI & $0.001(0.001-0.001)$ & $0.09(0.06-0.14)$ & $0.1(0.07-0.18)$ & $0.09(0.05-0.14)$ & $0.07(0.03-0.13)$ \\
\hline
\end{tabular}

Values are mean $\pm \mathrm{SD}$ or median (interquartile range).

${ }^{*} \mathrm{P}<0.05$ vs control group.

$\mathrm{POD}$, postoperative day; $\mathrm{Cr}$, creatinine; $\triangle \mathrm{Cr}$, difference from preoperative creatinine value; $\mathrm{CK}-\mathrm{MB}$, creatine kinaseMB. Other abbreviation see in Table 1.

whereas the number of patients treated with calcium-channel blockers was significantly less than in the Control group. Left ventricular EF was lower and preoperative EuroSCORE was higher in the RASI group compared with the Control group (Table 1).

Intraoperative variables, including anesthesia time, number of grafts and fluid balance, were similar between the groups. Significantly more norepinephrine was used during operation in the RASI group than in the Control group (Table 2).

After anesthetic induction and during obtuse marginalis (OM) artery anastomosis, MAP was lower and CVP and mean PAP were higher in the RASI group than in the Control group. After sternal closure, MAP was lower and mean PAP and PCWP were higher in the RASI group compared with the Control group. Other hemodynamic variables were comparable throughout surgery for each the group (Table 3 ).

Serum Cr levels were significantly higher in the RASI group at POD 0, 2 and 7, but $\Delta \mathrm{Cr}$ values were similar, except that the value at POD 7 was higher in the RASI group. The highest postoperative serum $\mathrm{Cr}$ levels were similar between the groups $(1.2 \pm 0.4 \mathrm{mg} / \mathrm{dl}$ vs $1.2 \pm 0.5 \mathrm{mg} / \mathrm{dl}$ in the Control and RASI groups, respectively, $\mathrm{P}=0.078) . \mathrm{CrCl}, \mathrm{CK}-\mathrm{MB}$ and
troponin-T levels were comparable between the groups throughout the study period (Table 4). A total of 416 patients received OM grafts and 56 patients did not. The incidence of AKI was similar between these 2 patients groups [87 (21.0\%) vs $11(19.2 \%), \mathrm{P}=0.241]$.

Duration of ICU and hospital stay, occurrence of postoperative AF, re-intubation and death, and the incidence of perioperative transfusion were not different between the groups. Milrinone was more frequently used during ICU stay in the RASI group than in the Control group (Table 5).

Because few patients were in stage 2 or 3 AKI according to the modified RIFLE classification, further analysis was performed between patients with and without postoperative AKI. In the unadjusted univariate analysis (Table 6), the risk factors significantly related with development of AKI were increasing age, female sex, presence of DM, left ventricular $\mathrm{EF}<0.35 \%$, preoperative $\mathrm{Cr}$ level and perioperative transfusion. In the multivariate analysis (Table 7), all of these variables were also significant risk factors for the development of AKI, except female sex, and preoperative treatment with RAS inhibitors did not increase the risk of postoperative AKI [OR, 0.841; 95\%CI 0.503-1.407; $\mathrm{P}=0.509$ ]. 


\begin{tabular}{lccc|}
\hline Table 5. Postoperative Outcomes & Control $(\mathbf{n}=\mathbf{1 7 6})$ & RASI $(\mathbf{n = 2 9 6 )}$ & P value \\
Duration of ICU stay (days) & $3.2 \pm 1$ & $3.6 \pm 3$ & 0.122 \\
Duration of hospital stay (days) & $11.4 \pm 4.2$ & $12.6 \pm 7.9$ & 0.264 \\
Postoperative milrinon use & $27(15.4)$ & $78(26.4)$ & 0.006 \\
Postoperative dialysis & $1(0.6)$ & $6(2.0)$ & 0.266 \\
Postoperative AKI, yes & $35(19.9)$ & $62(20.9)$ & 0.815 \\
Postoperative AF, yes & $37(21.3)$ & $61(21.1)$ & 0.968 \\
Death & $2(1.1)$ & $1(0.3)$ & 0.559 \\
Re-intubation & $2(1.1)$ & $6(2.0)$ & 0.716 \\
Red blood cell transfusion & $66(37.5)$ & $113(38.2)$ & 0.921 \\
\hline
\end{tabular}

Values are mean \pm SD or no. of patients (\%).

ICU, intensive care unit; AKI, acute kidney injury; AF, atrial fibrillation. Other abbreviation see in Table 1.

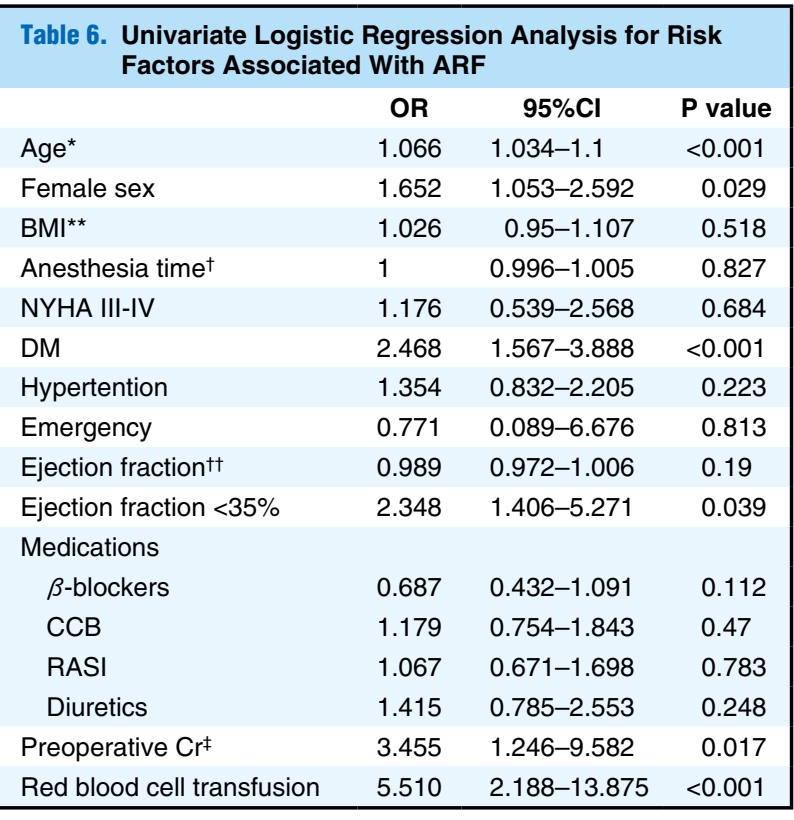

${ }^{*}$ Per 1 -year increase; ${ }^{* *}$ per $1-\mathrm{kg} / \mathrm{m}^{2}$ increase; ${ }^{\dagger}$ per 1 -min increase; ${ }^{\dagger+}$ per $1 \%$ increase; $\neq$ per $1-\mathrm{mg} / \mathrm{dl}$ increase.

OR, odds ratio; $\mathrm{Cl}$, confidence interval. Other abbreviations see in Tables 1, 4,5.

The propensity score for preoperative RAS inhibitor treatment achieved an acceptable discrimination between the 2 groups [C static, 0.66; 95\% CI 0.64-0.69; $\mathrm{P}<0.001]$. After adjusting for propensity score and covariates, DM, preoperative $\mathrm{Cr}$ level and perioperative transfusion were significant risk factors for postoperative AKI, whereas preoperative treatment with RAS inhibitors did not increase the risk of the AKI after OPCAB (OR, 0.335; 95\%CI 0.114-1.097; $\mathrm{P}=0.090)$. The multivariate model significantly predicted the occurrence of AKI (model $\left.\chi^{2}, 42.3 ; \mathrm{P}<0.001\right)$. The discriminatory ability of the logistic model was acceptable (C static, 0.83 ; 95\% CI $0.75-0.91 ; \mathrm{P}<0.001)$. The model was well calibrated among deciles of observed and expected risk (Hosmer-Lemeshow $\left.\chi^{2}, 8.15 ; \mathrm{P}=0.419\right)$.

\section{Discussion}

In the current study evaluating the effect of preoperative use of RAS inhibitors on the occurrence of AKI and postoperative renal function following $\mathrm{OPCAB}$, no negative influence was observed. Only DM, the preoperative $\mathrm{Cr}$ level, and peri-

\begin{tabular}{|c|c|c|c|c|}
\hline \multirow[t]{2}{*}{ Table 7.} & \multicolumn{4}{|c|}{$\begin{array}{l}\text { Multivariate Logistic Regression Analysis }{ }^{\star,, \star} \text { for Risk } \\
\text { Factors Associated With Acute Kidney Injury } \\
\text { Adjusted for Propensity Score }{ }^{\dagger} \text { to Receive } \\
\text { RASI Preoperatively }\end{array}$} \\
\hline & & OR & $95 \% \mathrm{Cl}$ & $P$ value \\
\hline $\mathrm{Age}^{\dagger \dagger}$ & & 1.020 & $0.944-1.102$ & 0.621 \\
\hline Female & sex & 1.414 & $0.463-4.319$ & 0.543 \\
\hline $\mathrm{BMI}{ }^{\ddagger}$ & & 1.111 & $0.928-1.330$ & 0.250 \\
\hline Anesthe & esia time & 0.999 & $0.979-1.002$ & 0.100 \\
\hline NYHA II & III-IV & 2.271 & $0.399-12.943$ & 0.356 \\
\hline DM & & 2.877 & $1.085-7.627$ & 0.034 \\
\hline Ejection & $n$ fraction $<35 \%$ & 1.646 & $0.142-19.053$ & 0.690 \\
\hline RASI & & 0.335 & $0.114-1.097$ & 0.090 \\
\hline Preoper & rative $\mathrm{Cr}^{n}$ & 29.611 & $3.369-260.293$ & 0.002 \\
\hline Red blo & ood cell transfusion & 6.274 & $1.862-21.148$ & 0.003 \\
\hline
\end{tabular}

${ }^{*}$ Model $\chi^{2}, 42.3, \mathrm{P}<0.001, \mathrm{C}$ static, 0.83; **Hosmer-Lemeshow $\chi^{2}$, $8.15, \mathrm{P}=0.419$; ${ }^{\mathrm{C}} \mathrm{C}$ static for propensity score, $0.66, \mathrm{P}<0.001$; ${ }^{\dagger}$ per 1 -year increase; $\neq$ per $1-\mathrm{kg} / \mathrm{m}^{2}$ increase; $\neq \neq$ per 1 -min increase; 7 per $1-\mathrm{mg} / \mathrm{dl}$ increase.

Abbreviations see in Tables 1,4,6.

operative transfusion remained as independent risk factors of AKI. Sustained preoperative treatment with RAS inhibitors, however, was associated with reduced intraoperative MAP and increased amount of vasoconstrictors used without any differences in postoperative outcome.

Despite advances in surgical techniques and postoperative care, AKI remains a major problem after cardiac surgery and is independently associated with increased morbidity and mortality. ${ }^{19,21}$ Thus, there is considerable interest in determining strategies that may decrease the incidence of AKI in cardiac surgery patients. Preoperative use of RAS inhibitors has been one of the investigated issues in terms of postoperative renal function, with contradictory results. Chronic therapy with RAS inhibitors has demonstrated benefit in reducing cardiovascular events in high-risk patients, ${ }^{3,4}$ and because patients undergoing $\mathrm{CABG}$ are increasingly older and have coexisting hypertension or heart problems, these drugs are more commonly used by patients who undergo CABG. There is evidence that preoperative RAS inhibitor therapy has benefits for $\mathrm{CABG}$ patients by preventing vasoconstriction, decreasing local tissue inflammation, and preserving endothelial function, ${ }^{22,23}$ despite the frequent development of systemic hypotension and associated problems. ${ }^{24,25}$ The renal protective effect of RAS inhibitors in long-term use has been proven and some studies have demonstrated that even intraoperative use of RAS inhibitors is reno-protective by improv- 
ing renal perfusion. ${ }^{23,26}$ Because the drugs block efferent arteriolar constriction and cause a decline in glomerular filtration, 5,6 however, preoperative RAS inhibitor therapy could impair the autoregulation of renal blood flow during CPB and exacerbate CPB-related renal hypoperfusion and injury. ${ }^{19}$ Indeed, there is a study reporting that long-term preoperative use of RAS inhibitors increased the risk of postoperative AKI by approximately $28 \%$ in cardiac surgery patients. ${ }^{2}$ The effect of preoperative use of RAS inhibitors on postoperative renal function is influenced by accompanying conditions affecting renal function, such as concomitant use of aprotinin, heart failure or volume depletion. ${ }^{15,16,27}$ Thus, avoiding CPB during OPCAB could moderate the effect of RAS inhibitors on postoperative renal function, although there has been scant evaluation of the effect of RAS inhibitors on the occurrence of postoperative AKI or postoperative renal function in OPCAB patients.

Recently, OPCAB has been preferentially performed in high-risk patients, with better postoperative outcomes compared with conventional CABG. ${ }^{8-10}$ Although a deleterious effect on renal function could be exerted during OPACB, because of transient circulatory failure and hypoperfusion during the period of the heart displacement for grafting, ${ }^{14,28}$ OPCAB has been reported as a protective factor against postoperative AKI. ${ }^{11-14}$ In the current study, RAS inhibitor therapy for at least 2 weeks preoperatively did not significantly affect postoperative renal function nor did it increase the incidence of AKI. Although serum Cr levels at POD 0, 2 and 7 were higher in the RASI group than in the Control group, it was unlikely to be clinically significant because the $\Delta \mathrm{Cr}$ was similar between the groups. Above all, in the unadjusted multivariate logistic regression analysis, preoperative use of RAS inhibitors was not related to increased risk of AKI after OPCAB. The finding of a similar incidence of AKI and postoperative renal function in the RASI group compared with the Control group, despite the more prevalent preoperative co-morbidities, further indicates that RAS inhibitors are not associated with a clinically significant increase in the risk of postoperative renal dysfunction. Even in our multivariate analysis adjusted for propensity score, RAS inhibitors did not increase the risk of the incidence of AKI after OPACB. Thus, the results of the current study clearly demonstrate that preoperative RAS inhibitor therapy might not be harmful in terms of postoperative renal function after OPCAB. This results would be associated with the lack of prolonged renal hypoperfusion caused by nonpulsatile blood flow and significant changes in intravascular volume status and vascular tone during $\mathrm{CPB}$ in OPCAB. Although MAP was lower and the amount of norepinephrine infused during operation was significantly larger in the RASI group than in the Control group in this study, MAP was maintained above $65 \mathrm{mmHg}$, even during $\mathrm{OM}$ anastomosis, and cardiac output and $\mathrm{SvO}_{2}$ were also maintained in the RASI group at levels comparable to those in the Control group, which might have offset the hemodynamic effect of RAS inhibitors on renal function in this study. Several studies have reported that the incidence and duration of transient circulatory failure and global hypoperfusion increased in cases of exposure of lateral vessels and this resulted in increased risk of postoperative renal impairment. ${ }^{28}$ In our study, however, there were no significant differences in the incidence of AKI between the patients receiving an OM graft and those who did not.

In this study, the occurrence of postoperative AKI was closely related to the presence of DM, the preoperative $\mathrm{Cr}$ level and perioperative transfusion. Identification of all these independent risk factors for AKI is concordant with the results of previous studies of conventional on-pump CABG. , $^{2,29-31}$

RAS inhibitors have been demonstrated to exert beneficial effects in terms of postoperative myocardial function through various mechanisms. Chronic RAS inhibitor treatment is reported to reduce myocardial infarct size and confer a myocardial protective effect during conventional CABG in terms of less increase in cardiac troponin-I levels; ${ }^{32}$ in the current study the postoperative CK-MB and troponin-T levels were similar. More frequent use of postoperative milrinone in the RASI group might be associated with the lower preoperative left ventricular EF in the RASI group. Long-term use of RAS inhibitors is reported to decrease the incidence of postoperative $A F,{ }^{33}$ but we could not find such a protective effect of these drugs.

\section{Study Limitations}

Being a non-blinded retrospective study, different types and doses of RAS inhibitors were used for various durations and randomization could not be performed. In this study, however, all possible parameters affecting postoperative renal function were prospectively controlled according to the institutional guidelines and recorded at predetermined times, unlike other previous retrospective reviews. ${ }^{2,7}$ Furthermore, random allocation of patients to the medication group without regard to the patient's condition or ceasing medications would not be ethical.

In conclusion, preoperative use of RAS inhibitors did not increase the risk of AKI after OPCAB and did not aggravate postoperative renal dysfunction, which was only associated with the presence of DM, the preoperative Cr level and perioperative transfusion. These findings imply that OPCAB is a safe alternative to on-pump CABG without an additionally increased risk of developing AKI in patients who would benefit from continued RAS inhibitor therapy.

\section{References}

1. Smith SC Jr, Allen J, Blair SN, Bonow RO, Brass LM, Fonarow $\mathrm{GC}$, et al. AHA/ACC guidelines for secondary prevention for patients with coronary and other atherosclerotic vascular disease: 2006 update endorsed by the National Heart, Lung, and Blood Institute. J Am Coll Cardiol 2006; 47: 2130-2139.

2. Arora P, Rajagopalam S, Ranjan R, Kolli H, Singh M, Venuto R, et al. Preoperative use of angiotensin-converting enzyme inhibitors/ angiotensin receptor blockers is associated with increased risk for acute kidney injury after cardiovascular surgery. Clin J Am Soc Nephrol 2008; 3: 1266-1273.

3. Mann JF, Gerstein HC, Yi QL, Lonn EM, Hoogwerf BJ, Rashkow A, et al. Development of renal disease in people at high cardiovascular risk: Results of the HOPE randomized study. J Am Soc Nephrol 2003;14: 641-647.

4. Fitchett D. Result of the ONARGET and TRANSCEND studies: An update and discussion. Vasc Health Risk Manag 2009; 5: 21 29.

5. Brown NJ, Vaughan DE. Angiotensin-converting enzyme inhibitors. Circulation 1998; 97: 1411-1420.

6. Toto R. Angiotensin II subtype 1 receptor blockers and renal function. Arch Intern Med 2001; 161: 1492-1499.

7. Benedetto U, Sciarretta S, Roscitano A, Fiorani B, Refice S, Angeloni E, et al. Preoperative angiotensin-converting enzyme inhibitors and acute kidney injury after coronary artery bypass grafting. Ann Thorac Surg 2008; 86: 1160-1165.

8. Stallwood MI, Grayson AD, Mills K, Scawn ND. Acute renal failure in coronary artery bypass surgery: Independent effect of cardiopulmonary bypass. Ann Thorac Surg 2004; 77: 968-972.

9. Tabata M, Takanashi S, Fukui T, Horai T, Uchimuro T, Kitabayashi $\mathrm{K}$, et al. Off-pump coronary artery bypass grafting in patients with renal dysfunction. Ann Thorac Surg 2004; 78: 2044-2049.

10. Horai T, Fukui T, Tabata M, Takanashi S. Early and mid-term results of off-pump coronary artery bypass grafting in patients with end stage renal disease: Surgical outcomes after achievement of 
complete revascularization. Interact Cardiovasc Thorac Surg 2008; 7: $218-221$.

11. Ramsay JG. The respiratory, renal, and hepatic systems: Effect of cardiac surgery and cardiopulmonary bypass. In: Mora CT, editor. Cardiopulmonary bypass. New York: Springer-Verlag, 1995; 147 168.

12. Ishida M, Kobayashi J, Tagusari O, Bando K, Niwaya K, Nakajima $\mathrm{H}$, et al. Perioperative advantages of off-pump coronary artery bypass grafting. Circ J 2002; 66: 795-799.

13. Hayashida $\mathrm{N}$, Teshima $\mathrm{H}$, Chihara $\mathrm{S}$, Tomoeda $\mathrm{H}$, Takaseya $\mathrm{T}$, Hiratsuka R, et al. Does off-pump coronary artery bypass grafting really preserve renal function? Circ J 2002; 66: 921 -925.

14. Biglioli P, Cannata A, Alamanni F, Naliato M, Porqueddu M, Zanobini M, et al. Biological effects of off-pump versus on-pump coronary artery surgery: Focus on inflammation, haemostasis and oxidative stress. Eur J Cardiothorac Surg 2003; 24: 260-269.

15. Cruz CS, Cruz LS, Silva GR, Marcílio de Souza CA. Incidence and predictors of development of acute renal failure related to treatment of congestive heart failure with ACE inhibitors. Nephron Clin Pract 2007; 105: $77-83$.

16. Stirling C, Houston J, Robertson S, Boyle J, Allan A, Norrie J, et al. Diarrhea, vomiting and ACE inhibitors: An important cause of acute renal failure. J Hum Hypertens 2003; 17: 419-423.

17. Molitoris BA, Levin A, Warnock DG, Joannidis M, Mehta RL, Kellum JA, et al. Improving outcome of acute kidney injury: Report of an initiative. Nat Clin Pract Nephrol 2007; 3: 439-442.

18. Hoste EAJ, Kellum JA. Acute kidney injury: Epidemiology and diagnostic criteria. Curr Opin Crit Care 2006; 12: 531-537.

19. Rosner MH, Okusa MD. Acute kidney injury associated with cardiac surgery. Clin J Am Soc Nephrol 2006; 1: 19-32.

20. Nashef SA, Roques F, Michel P, Gauducheau E, Lemeshow S, Salamon R. European system for cardiac operative risk evaluation (EuroSCORE). Eur J Cardiothorac Surg 1999; 16: 9-13.

21. Chertow GM, Levy EM, Hammermeister KE, Grover F, Daley J. Independent association between acute renal failure and mortality following cardiac surgery. Am J Med 1998; 104: 343-348.

22. Morawietz H, Erbs S, Holtz J, Schubert A, Krekler M, Goettsch W, et al. Endothelial protection, AT1 blockade and cholesterol-dependent oxidative stress: The EPAS trial. Circulation 2006; 114: 296-301.

23. Ryckwaert F, Colson P, Ribstein J, Boccara G, Guillon G. Haemodynamic and renal effects of intravenous enalaprilat during coronary artery bypass graft surgery in patients with ischaemic heart dysfunction. Br J Anaesth 2001; 86: 169-175.

24. Tuman KJ, McCarthy RJ, O'Connor CJ, Holm WE, Ivankovich AD Angiotensin-converting enzyme inhibitor increase vasoconstrictor requirement after cardiopulmonary bypass. Anesth Analg 1995; 80: 473-479.

25. Raja SG, Fida N. Should angiotensin converting enzyme inhibitors/angiotensin II receptor antagonists be omitted before cardiac surgery to avoid postoperative vasodilation? Interact Cardiovasc Thorac Surg 2008; 7: 470-475.

26. Wagner F, Yeter R, Bisson S, Siniawski H, Hetzer R. Beneficial hemodynamic and renal effects of intravenous enalaprilat following coronary artery bypass surgery complicated by left ventricular dysfunction. Crit Care Med 2003; 31: 1421-1428.

27. Kincaid EH, Ashburn DA, Hoyle JR, Reichert MG, Hammon JW, Kon ND. Does the combination of aprotinin and angiotensin-converting enzyme inhibitor cause renal failure after cardiac surgery? Ann Thorac Surg 2005; 80: $1388-1393$.

28. Tang AT, Knott J, Nanson J, Hsu J, Haw MP, Ohri SK. A prospective randomised study to evaluate the renoprotective action of beating heart coronary surgery in low risk patients. Eur J Cardiothorac Surg 2002; 22: $118-123$.

29. Benedetto U, Luciani R, Goracci M, Capuano F, Refice S, Angeloni E, et al. Miniaturized cardiopulmonary bypass and acute kidney injury in coronary artery bypass graft surgery. Ann Thorac Surg 2009; 88: 529-535.

30. Oyamada S, Kobayashi J, Tagusari O, Nakajima H, Nakamura $\mathrm{S}$, Yagihara $\mathrm{T}$, et al. Is diabetic nephropathy a predicted risk factor?: Kaplan-Meier and multivariate analysis of confounding risk factors in off-pump coronary artery bypass grafting for chronic dialysis patients. Circ J 2009; 73: 2056-2060.

31. Furukawa Y, Ehara N, Taniguchi R, Haruna Y, Ozasa N, Saito N, et al. Coronary risk factor profile and prognostic factors for young Japanese patients undergoing coronary revascularization. Circ J 2009; 73: $1459-1465$.

32. Benedetto U, Melina G, Capuano F, Comito C, Bianchini R, Simon $\mathrm{C}$, et al. Preoperative angiotensin-converting enzyme inhibitors protect myocardium from ischemia during coronary artery bypass graft surgery. J Cardiovasc Med 2008; 9: 1098-1103.

33. Ozaydin M, Dede O, Varol E, Kapan S, Turker Y, Peker O, et al. Effect of renin-angiotensin aldosterone system blockers on postoperative atrial fibrillation. Int J Cardiol 2008; 127: 362-367. 